\title{
Analysis of Risk Factors Sociodemographic for the Functional Dependence of Adults with Spinal Cord Injury
}

\author{
Roberta de Araújo e Silva ${ }^{1,2}$, Priscila Alencar Mendes Reis ${ }^{1}$, \\ Zuila Maria de Figueiredo Carvalho', Ana Karina Bezerra Pinheiro', \\ Lorena Barbosa Ximenes ${ }^{1}$, Maria Aparecida Alves de Oliveira ${ }^{2}$ \\ ${ }^{1}$ Federal University of Ceará, Fortaleza, Brazil \\ ${ }^{2}$ Federal University of Maranhão, Imperatriz, Brazil \\ Email: roberta.2010@yahoo.com.br, zmfca@fortalnet.com.br, prialencarmendes@hotmail.com, \\ anakarinaufc@hotmail.com, lbximenes2005@uol.com.br
}

Received 19 March 2015; accepted 14 April 2015; published 15 April 2015

Copyright (C) 2015 by authors and Scientific Research Publishing Inc.

This work is licensed under the Creative Commons Attribution International License (CC BY). http://creativecommons.org/licenses/by/4.0/

\section{Open Access}

\section{Abstract}

Objective: To evaluate the odds ratio of risk factors of sociodemographic and functional capacity of adults with spinal cord injury. Methods: Analytical, cross-sectional, quantitative study accomplished with a group of 47 people with spinal cord injury in hospitals and 27 in the household. The data were collected through a structured instrument composed of independent variables related to epidemiological and clinical data on spinal cord injury and dependent variables corresponding to the scale of the Barthel Index (BI). The data were analysed with the two-tailed chi-square or Fisher's exact tests using the Statistical Package for the Social Sciences version 20.0 (SPSS Inc., USA). Odds ratio (OR) and $95 \%$ confidence intervals (CI) were used as an estimate of the risk. The level of significance was set at a $p$ value $\leq 0.05$. Results: It was found that males $(O R=4.804, p=$ $0.041)$, the education less than ten years $(O R=3.000, p=0.036)$, the hospital care $(O R=5.250, p=$ 0.002 ) and injury time less than six months $(O R=5.250, p=0.002)$ are sociodemographic factors that are associated with the functional capacity of individuals with spinal cord injury. Moreover, the total dependence $(p<0.001)$ and severe dependence $(p=0.019)$ are associated with quadricplegia. It was found that males $(p=0.041)$, the education less than ten years $(p=0.036)$, attention to hospital health $(p=0.002)$ and minor injury time less than six months $(p=0.002)$ are sociodemographic factors associated with functional capacity of subjects. Conclusion: As a result, it was found that knowing the epidemiological and clinical factors of people with spinal cord injury is relevant to plan the nursing care. In other words, knowing the epidemiological and clinical factors of people with spinal cord injury is relevant to achieve the functional independence of these people, and it was demonstrated that the social determinants of health are interrelated and interdependent of chronic health conditions, as evidenced by the Care Model for Chronic Conditions. 


\section{Keywords}

\section{Spinal Cord Injury, Health Promotion, Social Determinants of Health, Nursing}

\section{Introduction}

The Spinal Cord Injury is a disabling neurological syndrome, considered as a chronic health condition, as it predisposes the individual to a functional disability condition, which causes several degrees of dependency due to physical and functional limitations. [1] [2].

It is known that the functional impairments resulting from spinal cord injury also vary according to age, sex, marital status, education, occupation, type and time of injury, among other epidemiological and clinical factors [3]-[5].

The current literature shows that social determinants of health have an influence over chronic health conditions; this theme is discriminated on the Care Model for Chronic Conditions (MACC, in Portuguese), originating in the Chronic Care Model [3] of the Risk Pyramid Model (MPR, in Portuguese) and the Social Model of Health Determination (DSS, in Portuguese) Dahlgren and Whitehead [6].

The MACC is divided into five levels according to the subpopulations and their different risks. In the first level, the total population will intervene on the social determinants of health intermediaries. The second level is represented by the subpopulations with different risk factors linked to behaviors and lifestyles (social determinants of health proximal). The third level is with the subpopulations of people with individual risks and/or with established chronic condition, but with low and medium risk. The fourth level is with the subpopulations of people with established chronic condition, but of high and very high risk; and finally the last level is with subpopulations of complex health conditions [6].

This present study focuses on the fourth level, where there are subpopulations of people with established chronic condition of high and very high risk, such as the situation of people with SCI. At this level, there is a balance between supporting self-care and professional care, requiring a cooperative attention of the general primary health care and specialists, called Health Condition Management [6].

In this context, self-care can be measured by instruments that provide an overview of the patient's condition because of the injury and thus detects functional disabilities that it has in performing daily activities. In the present study, we used the Barthel Index (BI) to establish the level of functional dependence, which determines the chronic spinal cord injury [7] [8].

From the foregoing, the current study aimed to evaluate the odds ratio of epidemiologic risk factors, clinical and functional capacity of adults with spinal cord injury. In this perspective, knowledge of associations between the findings can support the (re)orientation of health care, with a view of prevention, promotion and maintenance of health of people with spinal cord injury.

\section{Methods}

\subsection{Design}

This is a cross-sectional study with a quantitative approach conducted in two environments: in hospitals, specifically in the neurology unit, located in a general, public and tertiary level hospital, reference in Emergency and Emergency traumatology for the Northeast of Brazil, in Fortaleza, Ceará, Brazil; and in the home environment of people affected by spinal cord injury residing in that city.

\subsection{Participants}

The sample of such study included 74 people with a diagnosis of traumatic spinal cord injury, where 47 were hospitalized and 27 were at home. The participation in this study was limited to those who met the following inclusion criteria: age over 18 years; have been affected by the injury for more than a week; be with preserved cognition. The exclusion criteria was conceded to those who had other trauma or other associated conditions that may impair the motor function, sensory and psychic of the person; persons who at the time of data collection showed clinical instability and people who changed without a possibility of contact address. 


\subsection{Measurements}

Data collection was through the interview technique with the use of a structured instrument composed of independent variables related to epidemiological and clinical data on spinal cord injury and dependent variables corresponding to the scale of the Barthel Index (BI).

The Barthel Index compares ten items of Activities of Daily Living (ADL) involving mobility and personal care, including: feeding, personal hygiene, bladder (control of the bladder sphincter), intestines (control of the anal sphincter), movement (bed-chair transfers), mobility/walking (use wheelchair), use of toilet (use the toilet), dressing, bathroom and stairs (capacity up and down stairs). The bath and personal care items are scored 0 or 5 , movement and mobility/march with $0,5,10$ or 15 , and the other with 0,5 or 10 . The total score ranges from 0 to 100, with scores between 0 to 20 means total dependence, 21 to 60 means severe dependence, 61 to 90 means moderate dependence, and 91 to 99 or 100 means weak dependence and independent [7]-[10].

In this study was used as a cutoff point the mark of 60 points on the Barthel Index, which is a turning point on which there is a shorter period of hospitalization and a greater likelihood to return to live in the community after discharge. With a score above 60, most patients are independent for essential personal care as travel without aid, feeding, personal care and sphincter control [7] [11].

\subsection{Data Analysis}

The statistical analysis was obtained through the software Statistical Package for the Social Sciences (SPSS), version 20.0. The numerical variables were presented as the central tendency and dispersion. The nominal and ordinal variables were expressed as the odds ratio to verify the associations between them using the chi-square test and Fisher's exact test (for prevalence under five); adopted the confidence interval of 95\% and was considered $\mathrm{p}<0.05$ as statistically significant.

The project was approved by the Ethics Committee in Research of Dr. José Frota Hospital under Protocol \#150147/2009 and the Ethics Committee in Research (COMEPE, in Portuguese) of the Federal University of Ceará, under protocol \#44/10.

\section{Results}

Is exhibited the situational analysis of health conditions through the study of odds ratio of clinic and epidemiologic risk factors related to functional capacity.

On Table 1 , is observed that sex $(p=0.041)$, education $(p=0.036)$, health care $(p=0.002)$ and injury time ( $p$ $=0.002$ ) are risk factors sociodemographic associated with the functional capacity of individuals. It revealed that the chance of an adult with spinal cord injury become dependent is: 4.8 times higher in male sex; 3 times higher in people with education inferior to 10 years of study; 5.2 times higher in hospital scope and with less than six months of spinal cord injury. The subjects of study presented age average of 36.32 years (SD = 13.32). It is important to note that $75 \%$ of sample had age up to 43 years. The data related to occupation and marital status, showed that in the article these are not associated with the functional capacity of people with spinal cord injury.

On Table 2, can be observed that total dependency $(p<0.001)$ and severe dependency $(p=0.019)$ are associated with the type of spinal cord injury. It revealed that the chance of a paraplegic have total dependency is 16.42 times smaller than a tetraplegic; and the chance of a paraplegic have severe dependency is 1.26 times smaller than a tetraplegic. The subjects of study showed Barthel Rate average score of $44.46(\mathrm{SD}=33.15)$. It is important to notice that $75 \%$ of sample had scope up to 75 , which means moderate dependency.

\section{Discussion}

In this study, it was observed that some risk factors sociodemographic influence the functional capacity of people with SCI. Therefore, this study shows a statistically significant association in factors sex, education, health care and injury time.

In the present study, the association between sex and education with the functional capacity shows a prevalence of functional dependence among people with SCI of males and with education level less than 10 years of education $(p<0.05)$. However, in the current literature there are three studies that correlated these variables, all pointed to the prevalence of functional independence. In the study that has applied the Competency Rating Scale for self-care (ASA, in Portuguese) [12] there was a predominance of males ( $p=0.028$ ); in the study that used 
Table 1. Evaluation of odds ratio for occurrence of functional dependency in adults with spinal cord injury, according to risk factors sociodemographic (Fortaleza, CE, Brazil, $2014(n=74)$ ).

\begin{tabular}{|c|c|c|c|c|c|c|}
\hline \multirow{3}{*}{$\begin{array}{c}\text { Risk Factors } \\
\text { Sociodemographic }\end{array}$} & \multicolumn{4}{|c|}{ Functional Capacity } & \multirow{3}{*}{ OR (CI-95\%) } & \multirow{3}{*}{$\mathbf{p}^{*}$} \\
\hline & \multicolumn{2}{|c|}{ Dependent } & \multicolumn{2}{|c|}{ Independent } & & \\
\hline & $\mathbf{N}$ & $\%$ & $\mathbf{N}$ & $\%$ & & \\
\hline \multicolumn{7}{|l|}{ Sex } \\
\hline Male & 49 & 66.3 & 17 & 22.9 & $4.804(1.036-22.274)$ & 0.041 \\
\hline Female & 3 & 4.0 & 5 & 6.8 & & \\
\hline \multicolumn{7}{|l|}{ Age } \\
\hline$<40$ years & 34 & 45.9 & 13 & 17.6 & $1.308(0.470-3.641)$ & 0.607 \\
\hline$\geq 40$ years & 18 & 24.3 & 9 & 12.2 & & \\
\hline \multicolumn{7}{|l|}{ Education } \\
\hline$<10$ years & 39 & 52.7 & 11 & 14.9 & $3.000(1.055$ - 8.532) & 0.036 \\
\hline$\geq 10$ years & 13 & 17.5 & 11 & 14.9 & & \\
\hline \multicolumn{7}{|l|}{ Occupation } \\
\hline Yes & 33 & 44.6 & 13 & 17.6 & $1.202(0.433-3.335)$ & 0.723 \\
\hline No & 19 & 25.6 & 9 & 12.2 & & \\
\hline \multicolumn{7}{|l|}{ Marital status } \\
\hline Without partner & 26 & 35.1 & 11 & 14.9 & $1.000(0.369-2.710)$ & 1.000 \\
\hline With partner & 26 & 35.1 & 11 & 14.9 & & \\
\hline \multicolumn{7}{|l|}{ Health care } \\
\hline Hospital & 39 & 52.7 & 8 & 10.8 & $5.250(1.789-15.332)$ & 0.002 \\
\hline At home & 13 & 17.5 & 14 & 19.0 & & \\
\hline \multicolumn{7}{|l|}{ Injury type } \\
\hline Paraplegia & 42 & 56.7 & 21 & 28.4 & $0.200(0.024-1.668)$ & 0.075 \\
\hline Tetraplegia & 10 & 13.5 & 1 & 1.4 & & \\
\hline \multicolumn{7}{|l|}{ Injury time } \\
\hline$<6$ months & 39 & 52.7 & 8 & 10.8 & $5.250(1.789-15.332)$ & 0.002 \\
\hline \multirow[t]{2}{*}{$\geq 6$ months } & 13 & 17.5 & 14 & 19.0 & & \\
\hline & Average & $\mathrm{SD}^{* *}$ & Median & $\mathbf{P} 25^{\dagger}$ & $\mathbf{P} 75^{\ddagger}$ & \\
\hline Age & 36.32 & 13.32 & 35.00 & 25.00 & 43.25 & \\
\hline
\end{tabular}

Dependent: total or severe dependency level; Independent: moderate, slight or independent level of dependency; *p-value $>0.05$ (Chi-square Test e Fisher Test); ${ }^{* *}$ SD: standard deviation; ${ }^{\dagger} \mathrm{P} 25$ : percentile 25; ${ }^{\ddagger} \mathrm{P} 75$ : percentile 75. 
Table 2. Evaluation of odds ratio for occurrence of different levels of functional dependency in adults with spinal cord injury, according to the type of spinal cord injury (Fortaleza, CE, Brasil, $2014(\mathrm{n}=74)$ ).

\begin{tabular}{|c|c|c|c|c|c|c|}
\hline \multirow{3}{*}{ Dependecy Levels } & \multicolumn{4}{|c|}{ Injury Type } & \multirow{3}{*}{ OR (CI-95\%) } & \multirow{3}{*}{$\mathbf{p}^{*}$} \\
\hline & \multicolumn{2}{|c|}{ Paraplegia } & \multicolumn{2}{|c|}{ Tetraplegia } & & \\
\hline & $\mathbf{N}$ & $\%$ & $\mathbf{N}$ & $\%$ & & \\
\hline \multicolumn{7}{|l|}{ Total Dependency } \\
\hline Yes & 18 & 24.3 & 10 & 13.5 & $16.429(2.221-121.540)$ & $<0.001$ \\
\hline No & 45 & 60.8 & 1 & 1.4 & & \\
\hline \multicolumn{7}{|l|}{ Severe Dependency } \\
\hline Yes & 22 & 29.7 & 0 & 0 & $1.268(1.102-1.460)$ & 0.019 \\
\hline No & 41 & 55.4 & 11 & 14.9 & & \\
\hline \multicolumn{7}{|l|}{ Moderate Dependency } \\
\hline Yes & 17 & 23.0 & 1 & 1.4 & 3.696 (0.439 - 31.085) & 0.202 \\
\hline No & 46 & 62,1 & 10 & 13.5 & & \\
\hline \multicolumn{7}{|l|}{ Independent } \\
\hline Yes & 6 & 8.1 & 0 & 0 & $1.193(1.075-1.324)$ & 0.286 \\
\hline \multirow[t]{2}{*}{ No } & 57 & 77.0 & 11 & 14.9 & & \\
\hline & Average & $\mathrm{SD}^{* *}$ & Median & $\mathbf{P} 25^{\dagger}$ & P75 & \\
\hline Barthel Rate & 44.46 & 33.15 & 42.50 & 15.00 & 75.25 & \\
\hline
\end{tabular}

${ }^{*}$ p-value > 0.05 (Chi-square Test e Fisher Test); **SD: standard deviation; ${ }^{\dagger} \mathrm{P} 25$ : percentile 25; ${ }^{\ddagger} \mathrm{P} 75$ : percentile 75.

the Functional Independence Measure (FIM) [13] it was prevailed females ( $=0.690)$ and the study that used the Barthel Index (BI) [14] the males are predominant $(\mathrm{p}=1.223)$. As for education level these studies showed the predominance of education level lower than 10 years of study, with its significance, ASA $(p=0.046)$; MIF $(\mathrm{p}>0.05)$ and IB $(\mathrm{p}=0611)$.

In other studies, in different contexts, it is observed the predominance of SCI in young men, aged between 20 and 40 years [15]-[18]. This fact confirm data obtained in this study showed that $87.8 \%$ of people with spinal cord injury were males with a prevalence of $63.5 \%$ under the age of 40 years and the average age was 36.62 years $(\mathrm{SD}=13.74)$.

These indicators consistent with the literature by showing that mostly victims of spinal cord injury are men affected in their most productive years, this fact can be explained because of the etiology of traumatic injuries, mainly due to the growing number of accidents and violence which young men are more exposed [18]-[21].

The chronic health conditions may be aggravated by lack of access to education and information, which affect the ability to adapt and acquire independence for everyday activities, so the coping of the health condition becomes impaired. It is also known that low education level interfere in other epidemiological factors with access to work and income, and therefore to obtain consumer goods and access to assistive technologies [13]-[15] [20].

In this study was observed that $62.1 \%$ of people reported some type of occupation, however, most of these people had been recently affected by SCI and found himself employed. However, studies show that after SCI, people have trouble keeping yourself busy effectively [17] [18].

Unemployment is a major concern of people with SCI, not only by the need to obtain their income, but also by the need to rescue your social identity and role. The occupation has a positive effect on social integration, quality of life and psychological well-being [17] [22].

The difficulty of reintegration into the labor market can be attributed to factors such as the own health condition and physical limitations, accessibility to transport, the existence of physical barriers or architectural, the ineffectiveness of public policies for the inclusion and reintegration of persons with disabilities in the labor market, 
as well as access to education and training. In addition, discrimination by employers and loss of benefits can also be attributed to the difficulty of reintegration [13] [17] [20].

A study conducted in São Paulo/Brazil with 60 people who have suffered traumatic SCI indicates that the difficulty in entering into the labor market and obtain income market is frequent for these individuals, as most of them had a low level of education (63.3\%), were beneficiaries of social security (63.3\%) and had some occupation (36.7\%), including informal activities such as street vendor [23].

Therefore, these factors are relevant to the (re)directing public health policies for people with SCI in the clinical, social and political context. These aspects of education are also shown in other studies that show that the majority had low level of education (63.3\%) [23] [24]. In Latin America, it is detected that $88 \%$ of 85 million people with disabilities do not have proper health care, and that $10 \%$ of the population lack access to citizenship rights. Consequently, there is a correlation in the level of education, poverty and disability are strongly articulated [20] [24].

With regard to marital status, the frequencies found were equivalent distributions between categories when the variable was dichotomized into "with a partner" and "unmarried", however [12], the literature [14] [18] shows that most people with SCI living without a partner, especially women.

In clinical aspects is also observed a statistically significant association in health care scope and injury time. In hospital scope of health care was observed greater functional dependence in the home environment $(\mathrm{p}=$ 0.002), as most of the participants of this study found in the acute phase of the SCI. However, this study is divergent from the before mentioned studies, which showed functional independence. Those using ASA [12] IB and [14] have been developed in the home environment with people over 10 years of injury, in other words, people in the chronic phase of SCI; and the one using the MIF [13] was developed in a rehabilitation hospital with people who was entering the program, which had a general functional improvement because the mobility progress acquired through the program.

In this study, the injury time less than six months the lesion has an association with the functional dependence ( $p=0.002)$. In the study using ASA [12], this correlation was also evident ( $p=0.020)$, so the longer injury time is predictive of functional independence, a fact that is justified by the adaptation process, coping strategies built with time and maturity [13] [25].

A study conducted in São Paulo/Brazil shows that the injury time interferes with functional independence without the need for rehabilitation in people over 13 months of SCI. However, clinical practice shows that early inserts in rehabilitation programs has a great value in predicting functional independence [16] [26].

Although the analysis of the type of injury and the functional capacity shown in Table 1 does not show statistically significant importance, that is opposed to clinical practice, a fact that led to a deep analysis, performing association of the type of injury and the functional capacity by the stratum of dependence level, as shown in Table 2. Thus, highlights the relevance of total dependence $(\mathrm{p}<0.001)$ and severe dependence $(\mathrm{p}<0.019)$ with te-traplegia.

In the literature it is observed that there is reliance on self-care capacity for tetraplegia $(p=0.012)$ [12]. Others have shown that patients suffering cervical level of SCI showed higher functional dependence motor than in the thoracic and lumbar levels. The level of neck injury, which corresponds to severe quadriplegia, means aggravating related impairment of physiological functions such as breathing pattern basic hemodynamic balance, among others. Therefore, it is imperative to follow these patients to minimize the potential for complications [13].

Studies evaluating the results of rehabilitation of persons with SCI showed significant increases in functional capacity regardless of the type of injury, however noted that people with tetraplegia stay longer in the rehabilitation center [16] [27] [28].

The nursing care for people with physical and functional limitations in both the acute and the chronic phase. Their actions are directed to favoring the recovery and adaptation to the limitations imposed by the disability and to meet the functional needs, motor, psychosocial and spiritual [26] [29]-[32].

The nurse seeks to promote the independence of the person with SCI in relation to the physical limits imposed by cognitive and behavioral disabilities, with the aim of helping the person to become independent as much as possible within their conditions and limitations; also promote and encourage self-care through guidelines and training situations; and enable the person to a social life, family in the best possible way and quality [26] [29][32].

The limitations of this study are generated due to the inability to determine the directionality of the associa- 
tions, as may occur the risk of bias of reverse causality, since risk factors, protection and outcomes are checked concurrently (typical limitation of cross-sectional study). Furthermore, they can also be considered limited number of participants to be specific population.

\section{Conclusions}

Knowing the sociodemographic factors of people with spinal cord injury is relevant to the planning of nursing care; in order to achieve functional independence of these, people should consider these aspects of nurses during the execution of the nursing process with a view to self-defense, self-care, the provision of basic needs and recreational activities, because the success of its implementation will contribute to the reduction of the limitations that these people face.

Finally, this study achieved its goals, as the analysis of epidemiological and clinical factors of spinal cord injury showed how the social determinants of health are interrelated and interdependent of chronic health conditions.

Therefore, improving the health of these people requires transforming a health care system fragmented and focused on the disease to another system that is proactive, integrated, continuous, focused on person and family and aimed at promoting and maintaining health as proposed by the Care Model for Chronic Conditions.

\section{Conflicts of Interest}

The authors declare that there are no conflicts of interest regarding the publication of this paper.

\section{Acknowledgements}

The authors would like to thank the Foundation for Scientific and Technological Development (FUNCAP), the National Council for Scientific and Technological Development (CNPq) and the Federal University of Ceará (UFC) for their support in the Master's Scholarships, for the opportunity to develop this research.

\section{References}

[1] Ballester, E.C., Periz, L.A., Codinachs, M.C., Fonts, L.C. and Alonso, M.P. (2009) Evaluation of the Degree of Functional Autonomy of Chronic Renal Patients According to Barthel, Lawton Indices and the Scale of the Dependence Act. Revista Sociedade Española Enfermería Nefrológica, 12, 104-110.

[2] Figueiredo Carvalho, Z.M., Moraes, P.O.F., Rolim, G.A. and Almeida, P.C. (2008) Accesibilidad Wheelchair in Clinics and Neurology and Neurosurgery Fortaleza Brazil. Enfermería Global, 7, 1-14.

[3] França, I.S.X., Coura, A.S., Sousa, F.S., Almeida, P.C. and Pagliuca, L.M.F. (2013) Quality of Life in Patients with Spinal Cord Injury. Revista Gaúcha Enfermagem, 34, 155-163. http://dx.doi.org/10.1590/S1983-14472013000100020

[4] Blanes, L., Carmagnani, M.I.S. and Ferreira, L.M. (2009) Quality of Life and Self-Esteen of Persons with Paraplegia Living in São Paulo, Brazil. Quality of Life Research, 18, 15-21. http://dx.doi.org/10.1590/S1983-14472013000100020

[5] Schoeller, S.D., Bitencourt, R.N., Leopardi, M.T., Pires, D.P. and Zanini, M.T.B. (2012) Changes in the Life of People with Acquired Spinal Cord Injury. Revista Eletrônica de Enfermagem, 14, 95-103.

[6] Mendes, E.V. (2012) The Care of Chronic Conditions in Primary Care: The Imperative of Strengthening the Strategy of Family Health. Organização Pan-Americana da Saúde, Brasília.

[7] Ruzafa, J.C. and Moreno, J.D. (1997) Evaluating Physical Disabilities: The Barthel Index. Revista Española de Salud Pública, 71, 127-137.

[8] Paz, L.M., et al. (2005) Press Nursing and Application of Barthel Index Patients with Spinal Cord Injury in Spinal Cord Clinic CIREN. Medwave, 5.

[9] Coura, A.S., França, I.S.X., Enders, B.C., Barbosa, M.L. and Souza, J.R.S. (2012) Incapacidade funcional e associações com aspectos sociodemográficos em adultos com lesão medular. Revista Latino-Americana de Enfermagem, 20, 84-92. http://dx.doi.org/10.1590/S0104-11692012000100012

[10] Rodrigues, G., Winck, J.C., Silveira, F. and Almeida, J. (2012) Sociological Evaluation of Patients with Amyotrophic Lateral Sclerosis. Revista Portuguesa de Pneumologia, 8, 645-653.

[11] Araújo, F., Ribeiro, J.L.P., Oliveira, A. and Pinto, C. (2007) Validation of the Barthel Index in a Sample of Non-Institutionalized Elderly. Revista Portuguesa de Saúde Pública, 25, 59-66.

[12] Coura, A.S., Enders, B.C., França, I.S.X., Vieira, C., Dantas, D.N.A. and de Menezes, D.J.C. (2013) Ability for 
Self-Care and Its Association with Sociodemographic Factors of People with Spinal Cord Injury. Revista da Escola de Enfermagem da USP, 47, 1150-1157. http://dx.doi.org/10.1590/S0080-623420130000500020

[13] Silva, G.A., Schoeller, S.D., Gelbcke, F.L., de Carvalho, Z.M.F. and de Jesus Paula da Silva, E.M. (2012) Functional Assessment of People with Spinal Cord Injury: Use of the Functional Independence Measure-FIM. Texto \& ContextoEnfermagem, 21, 929-936. http://dx.doi.org/10.1590/S0104-07072012000400025

[14] Coura, A.S., França, I.S.X., Enders, B.C., Barbosa, M.L. and Souza, J.R.S. (2012) Functional Disability of Adult Individuals with Spinal Cord Injury and Its Association with Socio-Demographic Characteristics. Revista Latino-Americana de Enfermagem, 20, 84-92. http://dx.doi.org/10.1590/S0104-11692012000100012

[15] Campos, R.R., Miranda, M.C., Carvalho, Z.M.F. and Vall, J. (2013) Depressive Symptoms in People with Chronic Spinal Cord Injury. Cogitare Enfermagem, 18, 433-438.

[16] Rabeh, S.A.N. and Caliri, M.H.L. (2010) Functional Ability in Individuals with Spinal Cord Injury. Acta Paulista de Enfermagem, 23, 321-327. http://dx.doi.org/10.1590/S0103-21002010000300002

[17] Xeira, A.R., Alves, J.B., Santos, A. and Gestalotero, J. (2014) Traumatic Spinal Cord Injury: The Impact of Sociodemographic Variables on the Adjustment and Mental Health of Subjects Affected. Psicologia, Saúde \& Doenças [Online], 15, 110-120.

[18] Vall, J., Costa, C.M.C., Pereira, L.F. and Friesen, T.T. (2011) Application of International Classification of Functioning, Disability and Health (ICF) in Individuals with Spinal Cord Injury. Arquivos de Neuro-Psiquiatria [Online], 69, 513-518. http://dx.doi.org/10.1590/S0004-282X2011000400020

[19] Silva, R.A., Carvalho, Z.M.F., Almeida, M.I., Monteiro, M.G.S. and Carvalho Júnior, J.F. (2012) Public Policies for Social Inclusion of Handicapped People-Systematic Review. Avances en Enfermería, 30, 13-24.

[20] Borges, A.M.F., Brignol, P., Schoeller, S.D. and Bonetti, A. (2012) People with Spinal Cord Injury and the Different Perceptions about Their Condition. Revista Gaúcha de Enfermagem, 33, 119-125. http://dx.doi.org/10.1590/S1983-14472012000300016

[21] Silva, A.C.C.M., Brasil, V.V., Minamisava, R., Oliveira, L.M., Cordeiro, J.A.B.L. and Barbosa, M.A. (2012) Quality of Life and Psychological Trauma in Firearm Violence Victims. Texto \& Contexto Enfermagem, Florianópolis, 21, 558-565.

[22] Ottomanelli, L., Barnett, S.D. and Goetz, L.L. (2013) A Prospective Examination of the Impact of a Supported Employment Program and Employment on Health-Related Quality of Life, Handicap, and Disability among Veterans with SCI. Quality of Life Research, 22, 2133-2141. http://dx.doi.org/10.1007/s11136-013-0353-5

[23] Blanes, L., Carmagnani, M.I.S. and Ferreira, L.M. (2009) Quality of Life and Self-Esteem of Persons with Paraplegia Living in São Paulo, Brazil. Quality of Life Research, 18, 15-21. http://dx.doi.org/10.1007/s11136-008-9411-9

[24] Elias, M.P., Monteiro, L.M.C. and Chaves, C.R. (2008) Accessibility of Legal Benefits Available in Rio de Janeiro for Physically Handicapped People. Ciência \& Saúde Coletiva, 13, 1041-1050. http://dx.doi.org/10.1590/S1413-81232008000300027

[25] Vera, R.S. and Araújo, T.C.C.F. (2011) Coping and Spinal Cord Injury: A Cross-Sectional Study with Rehabilitation Patients. Comunicação em Ciências da Saúde, 22, 211-220.

[26] Morais, D.F., Melo Neto, J.S., Spotti, A.R. and Tognola, W.A. (2014) Predictors of Clinical Complications in Patients with Spinomedullary Injury. Coluna/Columna, 13, 139-142. http://dx.doi.org/10.1590/S1808-18512014130200404

[27] Pillastrini, P., Mugnai, R., Bonfiglioli, R., Curti, S., Mattioli, S., Maioli, M.G., et al. (2008) Evaluation of an Occupational Therapy Program for Patients with Spinal Cord Injury. Spinal Cord, 46, 78-81. http://dx.doi.org/10.1038/sj.sc.3102072

[28] Kirshblum, S.C., Priebe, M.M., Ho, C.H., Scelza, W.M., Chiodo, A.E. and Wuermser, L.A. (2007) Spinal Cord Injury Medicine. 3. Rehabilitation Phase after Acute Spinal Cord Injury. Archives of Physical Medicine and Rehabilitation, 88, S62-S70. http://dx.doi.org/10.1016/j.apmr.2006.12.003

[29] Kodama, C.M., Spuras, M.V. and Padula, M.P.C. (2009) Cares Given by Nurses for Rehabilitation Patients. Arquivos Médicos dos Hospitais e da Faculdade de Ciências Médicas da Santa Casa de São Paulo, 54, 100-106.

[30] Andrade, L.T., Araújo, E.G., Andrade, K.R.P., Soares, D.M. and Chianca, T.C. (2010) Role of Nursing in Physical Rehabilitation. Revista Brasileira de Enfermagem, 63, 1056-1060. http://dx.doi.org/10.1590/S0034-71672010000600029

[31] Miranda, F.L., Henriques, S.M., Abrahão, C.M., Gonçalves, N.D. and Tannure, M.C. (2010) Diagnoses and Nursing Interventions Identified in Patients with Spinal Cord Injury: Literature Systematic Review. Revista de Enfermagem UFPE [Internet], 4, 1101-1109.

[32] Carvalho, Z.M.F., Darder, J.J.T., Reis, P.A.M., Magalhães, S.R. and de Freitas Maniva, S.J.C. (2013) Experiencing a Traumatic Spinal Cord Injury-Analysis on the View of the Theory of Watson's Transpersonal Caring. Journal of Biomedical Science and Engineering, 6, 14-20. http://dx.doi.org/10.4236/jbise.2013.67A2002 